\title{
Impact of chemical agents for surface treatments on microhardness and flexural strength of root dentin
}

Ana Paula Marcheto MARCELINO João Felipe BRUNIERA Fuad Abi RACHED-JUNIOR Silvio Rocha Corrêa da SILVA Danielle Cristine MESSIAS

School of Dentistry, University of Ribeirão Preto, Ribeirão Preto, SP, Brazil.

Declaration of Interests: The authors certify that they have no commercial or associative interest that represents a conflict of interest in connection with the manuscript.

Corresponding Author:

Danielle Cristine Messias

E-mail:dcf.messias@gmail.com

DOI: 10.1590/1807-3107BOR-2014.vol28.0052

Submitted: Apr 01, 2014

Accepted for publication: Jul 03, 2014

Last revision: Aug 21, 2014

\begin{abstract}
This study assessed the cross-sectional Knoop microhardness and flexural strength of root dentin exposed to different surface treatments with chemical agents after biomechanical preparation. Root canals from human canines were biomechanically treated and divided into eight groups $(n=10)$ to receive one of the following dentin treatments: I. Deionized water (control); II. 5.25\% Sodium hypochlorite (NaOCl); III. NaOCl + 10\% Sodium ascorbate (SA); IV. SA; V. 2\% Chlorhexidine gel (CHX); VI. 37\% Phosphoric acid gel (PA) + CHX; VII. PA; and VIII. PA + NaOCl. The roots were sectioned to obtain specimens that were evaluated for cross-sectional Knoop microhardness and flexural strength using a three-point bending test. ANOVA and Tukey's test were performed. The microhardness in the control group was significantly higher $(p<0.05)$ than in the groups exposed to chemical agents, which in turn were statistically similar $(p>0.05)$ to each other. Regarding flexural strength, $\mathrm{PA}+\mathrm{NaOCl}$ provided statistical higher values than $\mathrm{PA}+\mathrm{CHX}$ and $\mathrm{CHX}$. However, there was no significant difference between the control group and those groups subjected to surface treatment $(p>0.05)$. Dentin microhardness was reduced after exposure to $\mathrm{NaOCl}, \mathrm{CHX}, \mathrm{PA}, \mathrm{SA}$ and their associations and the flexural strength of radicular dentin was not affected by the chemical agents.
\end{abstract}

Keywords: Chemical Compounds; Physical Properties; Dentin.

\section{Introduction}

Most clinical failures in teeth restored with fiberglass posts occur due to post debonding. The durability and stability of resin bonded interfaces on dentin from the post space walls can be reached by improving the bond strength of the resin material to the root dentin ${ }^{1,2}$ during the cementation and by preserving the integrity of resin-dentin bonds. ${ }^{1}$ For this purpose, root dentin pretreatment with chemical agents has been suggested. ${ }^{3,4}$ However, despite the possible bond strength improvement, ${ }^{3,4,5,6,7}$ the mechanical properties of the treated dentin could be affected by the chemical substances.

The phosphoric acid etching of dentin surface removes hydroxyapatite, exposes the hydrated collagen network allowing hydrophilic adhesive penetration to form the hybrid layer. ${ }^{8}$ Nevertheless, degradation of resindentin bonds occurs over time due to hydrolysis of the collagen fibrils within the hybrid layer that are not fully infiltrated by resin monomers. ${ }^{1,9}$

Stable hybrid layer and preservation of adhesion can be reached by controlling the degradation of the denuded collagen matrix. ${ }^{10}$ Therefore, 
chlorhexidine digluconate (CHX) can inhibit the expression of endogenous matrix metalloproteinases $(\mathrm{MMPs})^{1,4,10}$ that are involved in the degradation of collagen in resin-dentin interfaces. ${ }^{11}$ Additionally, by applying $\mathrm{NaOCl}$ on the acid-demineralized dentin, ${ }^{12}$ the exposed collagen is removed, ${ }^{5}$ and the wettability of the bonding substrate ${ }^{9}$ and resin infiltration may be facilitated.

The exposure to antioxidant agents (e.g., $10 \%$ sodium ascorbate) has been proposed to increase the bond strength of resin materials to the dentin to reverse the oxidizing effect of $\mathrm{NaOCl}$-treated dentin surface, ${ }^{13}$ thereby neutralizing the residual chemical ${ }^{14}$ and reestablishing the compromised bond strength. ${ }^{15}$

Although the application of the aforementioned agents or their associations can preserve or improve the adhesion of resin materials to radicular dentin, ${ }^{3,4,5,6,7,16,17}$ changes in organic and mineral content caused by these chemicals ${ }^{18}$ could negatively affect the physical properties of dentin, thus causing root fragility.

Studies revealed a reduction in microhardness of radicular dentin exposed to $\mathrm{NaOCl}^{19,20}$ and $\mathrm{CHX}^{20}$ used as irrigating solutions. The degradation of the dental structure after $\mathrm{NaOCl}$ irrigation compromised the flexural strength..$^{21,22,23}$ However, it is not well established whether dentin pretreatment with chemical substances prior to adhesive cementation of fiber posts affects the mechanical properties of the biomechanically treated dentin.

Therefore, the aim of this study was to assess the impact of dentin surface treatment with chemical agents on cross-sectional Knoop microhardness and flexural strength of dentin after biomechanical preparation of root canals. The hypothesis was that the surface treatments do not affect the dentin microhardness and flexural strength negatively.

\section{Methodology}

The study protocol was approved by the local Ethics Committee (190.326).

\section{Specimen preparation}

Eighty maxillary canines were selected that had straight roots, completely formed apices, single canals, no calcifications or resorptions that had been confirmed radiographically; these canines were stored in $0.1 \%$ thymol solution. The clinical crowns were removed, and the root length was standardized to $14 \mathrm{~mm}$.

Instrumentation of the root canals was performed with Protaper system (Dentsply Maillefer -BallaiguesSwitzerland) at the working length determined visually by subtracting $1 \mathrm{~mm}$ from the root length of a size 15 K-file (Dentsply Maillefer, Ballaigues, Switzerland) at the apical foramen. Root canals were irrigated with $2 \mathrm{~mL}$ of $2.5 \%$ sodium hypochlorite between each file, followed by $5 \mathrm{~mL}$ of $17 \%$ EDTA for $5 \mathrm{~min}$. Final irrigation was completed with $10 \mathrm{~mL}$ of distilled water for 1 min, and the canals were dried with absorbent paper points (Dentsply Ind. e Com. Ltda., Petrópolis, Brazil).

\section{Dentin treatment with chemical agents}

The root apices were sealed with sticky wax (Wilson Polidental, Cotia, Brasil), and the dentin treatment was performed by flooding the root canal with the substance designed for each group $(\mathrm{n}=10)$, as follows:

1. GI) Deionized water (DW - control group): 10 $\mathrm{mL}$ of deionized water was inserted into the canal lumen for $10 \mathrm{~min}$;

2. GII) $5.25 \% \mathrm{NaOCl}(\mathrm{NaOCl}): 10 \mathrm{~mL}$ of $\mathrm{NaOCl}$ was inserted into the canal lumen for $5 \mathrm{~min}^{3}$;

3. GIII) $5.25 \% \mathrm{NaOCl}$ followed by $10 \%$ sodium ascorbate $(\mathrm{NaOCl}+\mathrm{SA}): \mathrm{NaOCl}$ was applied as described in GII, and $10 \mathrm{~mL}$ of sodium ascorbate was injected into the canal lumen for $10 \mathrm{~min}^{5}$;

4. GIV) $10 \%$ sodium ascorbate (SA). Sodium ascorbate was applied as described in GIII;

5. GV) $2 \%$ chlorhexidine digluconate gel ( $\mathrm{CHX}$ ): Chlorhexidine gel was applied to fill completely the root canal for $5 \mathrm{~min}^{3,4}$;

6. GVI) $37 \%$ phosphoric acid gel (PA): phosphoric acid gel was used to fill the root canal completely for $15 \mathrm{~s}$;

7. GVII) $37 \%$ phosphoric acid gel followed by $2 \%$ chlorhexidine gel $(\mathrm{PA}+\mathrm{CHX})$ : phosphoric acid gel was used as described in GVI. The gel was removed from the root canal by washing with deionized water for $15 \mathrm{~s}$. Chlorhexidine gel was applied as described in GV;

8. GVIII) $37 \%$ phosphoric acid gel followed by $5.25 \% \mathrm{NaOCl}(\mathrm{PA}+\mathrm{NaOCl})$ : phosphoric acid was applied to the root canal as described in GVI. $\mathrm{NaOCl}$ was injected as described in GII. 
Following the treatment, the root canals were washed with deionized water and stored in distilled water at $37^{\circ} \mathrm{C}$ for $24 \mathrm{~h}$.

Grooves were prepared along the long axis of the roots that were longitudinally cleaved in a buccolingual direction to expose the entire canal extension..$^{24}$ One half was used to assess microhardness while the other half was subjected to the flexural test.

\section{Cross-sectional Knoop microhardness measurement}

A $3 \mathrm{~mm}$-width segment from the cervical-middle region of each half was sectioned. The coronal portions of the specimens were ground with 400-, 600- and 1200-grit silicon carbide papers (3M, Sumaré, Brazil) and polished on cloths with a 0.3- $\mu \mathrm{m}$ alumina suspension (Alpha Micropolish, Buehler, Lake Bluff, USA). Dentin microhardness was measured with a Knoop indenter at $\times 40$ magnification (Shimadzu HMV-2000; Shimadzu Corporation, Kyoto, Japan) under a 10-g load and a 10-second dwell time. Three Knoop microhardness indents were made in a linear fashion at 200 $\mu \mathrm{m}$ from the root canal lumen along the horizontal line and spaced $200 \mu \mathrm{m}$ apart. The mean values of all three measuring points were then averaged.

\section{Flexural strength of dentin}

Each half of the root was longitudinally sectioned in a dentin bar $(10 \mathrm{~mm}$ long $\times 1.4 \mathrm{~mm}$ wide $\times 1.5 \mathrm{~mm}$ thick) from the cervical-middle area. The three-point bending flexural test was performed using an universal testing machine (Instron 4444; Instron Corporation, Canton, USA), with the distance between the center support points fixed at $8 \mathrm{~mm}$. The load cell was applied perpendicular to the long axis of the specimen with a $0.5 \mathrm{~mm} / \mathrm{min}$ crosshead speed until fracture. The flexural strength $\left(\sigma_{\mathrm{f}}\right)$ of the dentin was calculated using the following equation: $=\sigma_{\mathrm{f}}=3 F_{\max }$ $L / 2 \mathrm{bd}_{2}$ such that $F_{\max }$ is the maximum load in Newton, $\mathrm{L}$ is the distance between the support points in $\mathrm{mm}(8 \mathrm{~mm}), b$ is the specimen wide $(1.4 \mathrm{~mm})$ and $d$ is the specimen thickness $(1.5 \mathrm{~mm})$.

\section{Statistical analysis}

After checking the assumption of homogeneity of variance and normal distribution, microhardness and flexural resistance data were statistically analyzed by ANOVA and Tukey's test when significant differences were detected. The SPSS 17 software (SPSS Inc., Chicago, USA) was used to perform the statistical analyses at a 5\% significance level.

\section{Results}

\section{Cross-Sectional Microhardness}

One-way ANOVA revealed a significant difference between dentin treatments $(p<0.05)$.

The root dentin exposed to the deionized water had significantly higher $(p<0.05)$ microhardness than those treated with any other substance. These other groups did not have any statistically significant differences $(p>0.05)$ as shown in Table 1.

\section{Flexural Strength}

One-way ANOVA showed a significant difference in flexural strength $(p<0.05)$.

Tukey's test confirmed that $\mathrm{PA}+\mathrm{NaOCl}$ provided higher $(p<0.05)$ flexural strength than CHX and $\mathrm{PA}+\mathrm{CHX}$, which had the lowest values. The other groups presented intermediate values, and there was no statistically significant difference between them $(p>0.05)$. All chemical agents provided flexural strength similar to the deionized water $(p>0.05)$, as depicted in Table.

Table. Microhardness and flexural strength (MPa) values provided by each dentin treatment.

\begin{tabular}{lcc}
\hline Dentin Treatments & Microhardness & Flexural Strength \\
\hline $\mathrm{DW}$ & $104.1(21.2) \mathrm{A}$ & $221(29.5)^{\mathrm{ab}}$ \\
$\mathrm{NaOCl}$ & $53.6(10.5) \mathrm{B}$ & $209(30.4)^{\mathrm{ab}}$ \\
$\mathrm{NaOCl}+\mathrm{SA}$ & $53.2(10.6) \mathrm{B}$ & $197(29.4)^{\mathrm{ab}}$ \\
$\mathrm{SA}$ & $55.4(12.9) \mathrm{B}$ & $189(20.0)^{\mathrm{ab}}$ \\
$\mathrm{CHX}$ & $54.6(12.5) \mathrm{B}$ & $139(15.5)^{\mathrm{b}}$ \\
$\mathrm{PA}$ & $45.2(9.3) \mathrm{B}$ & $185(27.7)^{\mathrm{ab}}$ \\
$\mathrm{PA}+\mathrm{CHX}$ & $43.2(10.8) \mathrm{B}$ & $150(32.4)^{\mathrm{b}}$ \\
$\mathrm{PA}+\mathrm{NaOCl}$ & $45.5(8.1) \mathrm{B}$ & $246(41.6)^{\mathrm{a}}$ \\
\hline
\end{tabular}

Values are means \pm SD

bSignificant differences are expressed by different letters $(p<0.05)$, within each column. 


\section{Discussion}

Changes in mechanical properties of dentin can influence the behavior of the dentin/restoration interface. ${ }^{25}$ Additionally, the root resistance to fracture can be adversely affected by reduction in microhardness ${ }^{26}$ and flexural strength. ${ }^{21}$ The present study assessed the microhardness and flexural strength of root dentin exposed to chemical agents.

The hypothesis that the surface treatments do not negatively affect the dentin microhardness was rejected. Lower microhardness values were obtained by specimens exposed to chemical agents other than to deionized water. As microhardness is sensitive to the composition and surface changes of the tooth structure, ${ }^{27}$ alterations in the structure of root dentin achieved by chemical agents can reduce the microhardness, as observed in the present and previous investigations. ${ }^{19,20}$ In this study, although the dentin had already been exposed to irrigations with $\mathrm{NaOCl}$ and EDTA during biomechanical treatment of root canals, chemical surface treatments provided additional structural changes, thereby compromising the dentin microhardness. The reduction of dentin hardness following $\mathrm{NaOCl}$ treatment indicates potent direct effects on the organic and mineral content of dentin structures. ${ }^{18}$

The current results corroborate the findings from Oliveira et al. ${ }^{20}$ that verified reduced microhardness of dentin treated with $2 \% \mathrm{CHX}$ gel. $\mathrm{CHX}$ is a cationic compound that has the ability to bind anionic molecules, such as the phosphates present in the hydroxyapatite structure. ${ }^{18}$ Considering that phosphate is present in the calcium carbonate complex of dentin, $\mathrm{CHX}$ can induce changes in the $\mathrm{Ca} / \mathrm{P}$ ratio, ${ }^{18}$ which could explain the reduced values of microhardness in root dentin exposed to $\mathrm{CHX}$.

There is a lack of studies evaluating the effect of sodium ascorbate on the mechanical properties of dentin. Although reducing agents have been shown to not cause any additional changes in the structure ${ }^{13}$ and micromorphology of the dentin surface, a slightly increased roughness and more clearly visible collagen fibrils were verified.$^{28}$ The possible presence of exposed organic material can explain the decreased microhardness found in this investigation. Additionally, sodium ascorbate dissociates in ascorbic acid with low $\mathrm{pH}$, which could be contributed to demineralization of the dentin surface.

The compromised microhardness of the dentin treated with phosphoric acid was expected due to removal of the smear layer and the superficial part of the dentin, opening dentinal tubules, demineralizing the dentin surface and increasing the microporosity of the intertubular dentin. ${ }^{7}$ Subsequent studies may clarify the clinical relevance of the decreased microhardness.

Regarding the flexural strength, the radicular dentin treated with chemical agents did not differ from those exposed to deionized water, thereby supporting the hypothesis that the substances used in the dentin treatment do not compromise the flexural strength. These findings are in contrast to previous studies, which reported reduced flexural strength due to degradation of surface structures treated with $\mathrm{NaOCl}{ }^{21,22,23}$ Considering that the alterations in the mechanical properties of dentin are time dependent, ${ }^{22}$ the shorter application time used in the present investigation (10 $\mathrm{min}$ ) compared to other studies can justify the absence of negative effects of $\mathrm{NaOCl}$ on flexural strength.

Direct comparisons of the current findings with the literature could not be performed due to the lack of studies evaluating the flexural properties of dentin exposed to CHX, phosphoric acid, sodium ascorbate and their associations. To simulate the clinical protocol, the agents were applied to the dentin previously subjected to biomechanical treatment and irrigation with $2.5 \% \mathrm{NaOCl}$ and $17 \%$ EDTA. Moreira et al..$^{29}$ suggested a possible interaction between $\mathrm{CHX}$-based cavity disinfectants and endodontic irrigants, such as those used in this study during the biomechanical preparation, which could have promoted some structural alterations and affected the flexural strength.

The irrigation period has a crucial effect on dentin microhardness ${ }^{19}$ and flexural strength. ${ }^{23}$ Previous investigations indicated that short application times did not lead to significant changes in dentin mechanical properties. ${ }^{19,23}$ Considering that the agents evaluated in this study are used for the pretreatment of dentin in order to improve the adhesion process, the exposure of dentin to chemical substances was conducted for time periods to restore and improve the bond strength. ${ }^{2,3,4,5,6}$ The periods of exposure to 
treatment agents were based on previous investigations of dentin pretreatment with $\mathrm{NaOCl}_{1}^{3} \mathrm{CHX}_{1}^{3,4}$ phosphoric acid ${ }^{2}$ and sodium ascorbate. ${ }^{5}$

Other chemical agents and treatment protocols seemed to be important factors affecting the mechanical properties of the root dentin. However, additional studies should be conducted to evaluate the behavior of root dentin exposed to chemical agents and mainly the clinical relevance of these effects.

The present findings suggest that although Knoop microhardness of root dentin was adversely affected by chemical substances, the change in the hardness did not interfere with the flexural strength of the sub-

\section{References}

1. Toledano M, Osorio R, Albaladejo A, Aguilera FS, Osorio E. Differential effect of in vitro degradation on resin-dentin bonds produced by self-etch versus total-etch adhesives. J Biomed Mater Res A. 2006 Apr;77(1):128-35.

2. Osorio R, Yamauti M, Osorio E, Ruiz-Requena ME, Pashley D, Tay F, et al. Effect of dentin etching and chlorhexidine application on metalloproteinase-mediated collagen degradation. Eur J Oral Sci. 2011 Feb;119(1):79-85.

3. Cecchin D, Almeida JFA, Gomes BPFA, Zaia AA, Ferraz CCR. Deproteinization technique stabilizes the adhesion of the fiberglass post relined with resin composite to root canal. J Biomed Mater Res B Appl Biomater. 2011 Nov 21. Epub ahead of print.

4. Cecchin D, Giacomin M, Farina AP, Bhering CLB, Mesquita $\mathrm{MF}$, Ferraz CCR. Effect of chlorhexidine and ethanol on pushout bond strength of fiber posts under cyclic loading. J Adhes Dent. 2014 Feb;16(1):87-92.

5. Celik C, Erkut S, Gulsahi K, Yamanel K, Kucukesmen C. Effect of sodium ascorbate on bond strength of different adhesive systems to NaOCl-treated dentin. Aust Endod J. 2010 Apr;36(1):12-8.

6. Cecchin D, Almeida JFA, Gomes BPFA, Zaia AA, Ferraz CCR. Effect of chlorhexidine and ethanol on the durability of the adhesion of the fiber post relined with resin composite to the root canal. J Endod. 2011 May;37(5):678-83.

7. Pisani-Proença J, Erhardt MCG, Amaral R, Valandro LF, Bottino MA, Del Castillo-Salmerón R. Influence of different surface conditioning protocols on microtensile bond strength of self-adhesive resin cements to dentin. J Prosthet Dent. 2011 Apr;105(4):227-35.

8. Nakabayashi N, Nakamura M, Yasuda N. Hybrid layer as a dentin bonding mechanism. J Esthet Dent. 1991 Jul-Aug;3(4):133-8. strate. Considering that the flexural strength parameter determines the fracture resistance of a sample, ${ }^{30}$ the lack of difference from the control group (treated with deionized water) indicates that the fracture resistance was not affected by the chemical agents.

\section{Conclusions}

Within the limitations of an in vitro study, it may be concluded that the microhardness of dentin was reduced after exposition to $\mathrm{NaOCl}$, chlorhexidine, phosphoric acid, sodium ascorbate and associations, while flexural strength was not affected by the chemical agents.

9. Maior JRS, Figueira MAS, Braga Netto ABAB, Souza FB, Silva $\mathrm{CHV}$, Tredwin CJ. The importance of dentin collagen fibrils on the marginal sealing of adhesive restorations. Oper Dent. 2007 May-Jun;32(3):261-5.

10. Perdigão J, Reis A, Loguercio AD. Dentin adhesion and MMPs: a comprehensive review. J Esthet Restor Dent. 2013 Aug;25(4):219-41.

11. Pashley DH, Tay FR, Yiu C, Hashimoto M, Breschi L, Carvalho RM, et al. Collagen degradation by host-derived enzymes during aging. J Dent Res. 2004 Mar;83(3):216-21.

12. Perdigão J, Thompson JY, Toledano M, Osorio R. An ultramorphological characterization of collagen-depleted etched dentin. Am J Dent. 1999 Oct;12(5):250-5.

13. Moreira DM, Feitosa JPA, Line SRP, Zaia AA. Effects of reducing agents on birefringence dentin collagen after use of different endodontic auxiliary chemical substances. J Endod. 2011 Oct;37(10):1406-11.

14. Morris MD, Lee KW, Agee KA, Bouillaguet S, Pashley $\mathrm{DH}$. Effects of sodium hypochlorite and RC-prep on bond strengths of resin cement to endodontic surfaces. J Endod. 2001 Dec;27(12):753-7.

15. Garcia-Godoy F, Loushine RJ, Itthagarun A, Weller RN, Murray PE, Feilzer AJ, et al. Application of biologically-oriented dentin bonding principles to the use of endodontic irrigants. Am J Dent. 2005 Aug;18(4):281-90.

16. Leitune VCB, Collares FM, Samuel SMW. Influence of chlorhexidine application at longitudinal push-out bond strength of fiber posts. Oral Surg Oral Med Oral Pathol Oral Radiol Endod. 2010 Nov;110(5):77-81.

17. Stape THS, Menezes MS, Barreto BCF, Aguiar FHB, Martins LR, Quagliatto PS. Influence of matrix metalloproteinase synthetic inhibitors on dentin microtensile bond strength of resin cements. Oper Dent. 2012 Jul-Aug;37(4):386-96. 
18. Pascon FM, Kantovitz KR, Soares LES, Santo AME, Martin AA, Puppin-Rontani RM. Morphological and chemical changes in dentin after using endodontic agents: fourier transform Raman spectroscopy, energy-dispersive x-ray fluorescence spectrometry, and scanning electron microscopy study. J Biomed Opt. 2012 Jul;17(7):075008.

19. Slutzky-Goldberg I, Maree M, Liberman R, Heling I. Effect of sodium hypochlorite on dentin microhardness. J Endod. 2004 Dec;30(12):880-2.

20. Oliveira LD, Carvalho CAT, Nunes W, Valera MC, Camargo CHR, Jorge AOC. Effects of chlorhexidine and sodium hypochlorite on the microhardness of root canal dentin. Oral Surg Oral Med Oral Pathol Oral Radiol Endod. 2007 Oct;104(4):125-8.

21. Sim TPC, Knowles JC, Ng YL, Shelton J, Gulabivala K. Effect of sodium hypochlorite on mechanical properties of dentine and tooth surface strain. Int Endod J. 2001 Mar;34(2):120-32.

22. Marending M, Luder HU, Brunner TJ, Knecht S, Stark WJ, Zehnder M. Effect of sodium hypochlorite on human root dentine-mechanical, chemical and structural evaluation. Int Endod J. 2007 Oct;40(10):786-93.

23. Zhang K, Kim YK, Cadenaro M, Bryan TE, Sidow SJ, Loushine $\mathrm{RJ}$, et al. Effects of different exposure times and concentrations of sodium hypochlorite/ethylenediaminetetraacetic acid on the structural integrity of mineralized dentin. J Endod. 2010 Jan;36(1):105-9.
24. Cruz-Filho AM, Sousa-Neto MD, Savioli RN, Silva RG, Vansan LP, Pécora JD. Effect of chelating solutions on the microhardness of root canal lumen dentin. J Endod. 2011 Mar;37(3):358-62.

25. Marshall Júnior GW, Marshall SJ, Kinney JH, Balooch M. The dentin substrate: structure and properties related to bonding. J Dent. 1997 Nov;25(6):441-58.

26. Viapiana R, Sousa-Neto MD, Souza-Gabriel AE, Alfredo E, Silva-Sousa YTC. Microhardness of radicular dentin treated with 980-nm diode laser and different irrigant solutions. Photomed Laser Surg. 2012 Feb;30(2):102-6.

27. Cox CF, Heys DR, Gibbons PK, Avery JK, Heys RJ. The effect of various restorative materials on the microhardness of reparative dentine. J Dent Res. 1980 Feb;59(2):109-15.

28. Vongphan N, Senawongse P, Somsiri W, Harnirattisai C. Effects of sodium ascorbate on microtensile bond strength of total-etching adhesive system to $\mathrm{NaOCl}$ treated dentine. J Dent. 2005 Sep;33(8):689-95.

29. Moreira DM, Almeida JFA, Ferraz CCR, Gomes BPFA, Line SRP, Zaia AA. Structural analysis of bovine root dentin after use of different endodontics auxiliary chemical substances. J Endod. 2009 Jul;35(7):1023-7.

30. Plotino G, Grande NM, Bedini R, Pameijer CH, Somma F. Flexural properties of endodontic posts and human root dentin. Dent Mater. 2007 Sep;23(9):1129-35. 